\title{
Azacitidine as a bridge to allogeneic stem cell transplantation in a patient with juvenile myelomonocytic leukemia: a case report
}

\author{
Akira Takebayashi ${ }^{1}$, Tsukasa Hori ${ }^{2}$, Masaki Yamamoto ${ }^{1}$, Takeshi Tsugawa ${ }^{1}$, Keita \\ Igarashi $^{1}$, Kotoe Iesato ${ }^{1}$, Ryo Hamada ${ }^{1}$, Hideki Muramatsu ${ }^{3}$, and Yukihiko Kawasaki ${ }^{2}$ \\ ${ }^{1}$ Sapporo Medical University School of Medicine \\ ${ }^{2}$ Sapporo Medical University \\ ${ }^{3}$ Nagoya University Hospital
}

November 20, 2020

Submission type: Correspondence and Letters

Azacitidine as a bridge to allogeneic stem cell transplantation in a patient with juvenile myelomonocytic leukemia: a case report

Akira Takebayashi, $\mathrm{MD}^{1}$, Tsukasa Hori, MD, $\mathrm{PhD}^{1}$, Masaki Yamamoto, MD, $\mathrm{PhD}^{1}$, Takeshi Tsugawa, MD, $\mathrm{PhD}^{1}$, Keita Igarashi, $\mathrm{MD}^{1}$, Kotoe Iesato, $\mathrm{MD}, \mathrm{PhD}^{1}$, Ryo Hamada, $\mathrm{MD}^{1}$, Hideki Muramatsu, $\mathrm{MD}, \mathrm{PhD}^{2}$, Yukihiko Kawasaki, MD, $\mathrm{PhD}^{1}$

${ }^{1}$ Departments of Pediatrics, Sapporo Medical University School of Medicine, Sapporo, Japan

${ }^{2}$ Department of Pediatrics, Nagoya University Graduate School of Medicine, Nagoya, Japan

Corresponding author : Akira Takebayashi, MD, 291, South-1, West-16, Chuo-ku, Sapporo 060-8543, Japan. Phone: +81-11-611-2111; Fax: +81-11-611-0352; E-mail: take884akir@gmail.com

Key Words : JMML, juvenile myelomonocytic leukemia, azacitidine, bridge, bridging therapy, stem cell transplantation

Running title : Azacitidine as a bridging therapy to JMML

Words count : 488 words, 1 table.

Conflict of interest statement: The authors have no conflict of interest to declare.

To the Editor:

Juvenile myelomonocytic leukemia (JMML) is a rare myelodysplastic /myeloproliferative neoplasm in infants and toddlers. Allogeneic hematopoietic stem cell transplantation (HSCT) is the only curative therapy for most patients, but no appropriate pre-HSCT bridging therapy has been established. Since Furlan ${ }^{1}$ reported the effectiveness of azacitidine in pre-HSCT JMML, several reports have been published. Here we report a case of JMML treated with azacitidine.

A 6-month-old male presented with hepatosplenomegaly and thrombocytopenia. Laboratory examinations revealed monocytosis $\left(8.5 \times 10^{9} / \mathrm{L}\right)$, mild anemia (hemoglobin: $10.2 \mathrm{~g} / \mathrm{dL}$ ), thrombocytopenia $\left(17 \times 10^{9} / \mathrm{L}\right)$, and $11.7 \%$ hemoglobin F. Myeloblasts were peripheral blood: $2.0 \%$; bone marrow: $8.2 \%$. Fluorescence in situ hybridization detected monosomy-7 cells. Molecular analysis found a somatic KRAS p.G13D mutation, and he was diagnosed with JMML. 
We planned an unrelated bone marrow transplantation (UR-BMT) because an HLA-matched related donor was unavailable, and used 6-mercaptoprine (6-MP) as a bridging therapy. However, he still needed frequent transfusions and his hepatosplenomegaly was exacerbated (TABLE 1). We therefore changed the bridging therapy from 6-MP to azacitidine $(2.5 \mathrm{mg} / \mathrm{kg}$, over 1 hour intravenously on 7 consecutive days, every 28 days; TABLE 1). Platelet transfusion frequency decreased and he became transfusion-independent after azacitidine Cycle 6. Peripheral blood myeloblasts disappeared after Cycle 6, and the hepatosplenomegaly had completely improved after Cycle 8. Monosomy-7 cells significantly decreased, but did not disappear until his UR-BMT. He maintained clinical partial remission and genetic stable disease after Cycle 1, evaluated with response criteria defined by C. M. Niemeyer et al. Adverse effects of azacitidine included febrile neutropenia after Cycle 1 and exacerbated thrombocytopenia during Cycles 1 and 2. However, he suffered no adverse effects after Cycle 3.

UR-BMT from an HLA 7/8 matched donor was performed after azacitidine Cycle 8, when the patient was in partial remission. His conditioning regimen included busulfan, fludarabine and melphalan; a short course of methotrexate and tacrolimus was used as prophylaxis against for graft-versus-host disease. He remains in complete remission with complete donor chimerism at 27 months after UR-BMT.

Azacitidine is a DNA-hypomethylating agent used for myelodysplastic syndrome in adults, but is not generally used for JMML. Cseh reported twelve patients with JMML treated with azacitidine, ${ }^{3}$ of whom nine patients were treated with azacitidine before HSCT and five achieved partial or complete remission. The remaining four received HSCT during progressive disease after 1-4 cycles of azacitidine therapy. Although the optimal number of azacitidine cycles is unknown, continuing azacitidine therapy for six to eight cycles might be valuable if the patient can tolerate it.

Another infant with JMML, somatic KRAS mutation and monosomy-7 who achieved sustained remission following azacitidine monotherapy had been reported, ${ }^{4}$ but identifying patients who can sustain remission without HSCT is not currently possible. Reportedly, DNA methylation patterns in JMML can be predictive for prognosis, ${ }^{5,6}$ but whether they can predict response to hypomethylating agents or not is unclear. Although azacitidine bridging therapy is effective for JMML patients, further studies are needed to clarify several questions about JMML treatment.

\section{References}

1. Furlan I, Batz C, Flotho C, et al. Intriguing response to azacitidine in a patient with juvenile myelomonocytic leukemia and monosomy7. Blood 2009; 113(12): 2867-2868. doi: 10.1182/blood-2008-12-195693.

2. Niemeyer CM, Loh ML, Cseh A, et al. Criteria for evaluating response and outcome in clinical trials for children with juvenile myelomonocytic leukemia. Haematologica 2015; 100(1): 17-22. doi: 10.3324/haematol.2014.109892.

3. Cseh A, Niemeyer CM, Yoshimi A, et al. Bridging to transplant with azacitidine in juvenile myelomonocytic leukemia: a retrospective analysis of the EWOG-MDS study group. Blood 2015; 123(14): 2311-3. doi: 10.1182/blood-2015-01-619734.

4. Hashmi SK, Punia JN, Marcogliese AN, et al. Pediatr Blood Cancer 2019; 66(10): e27905 doi: $10.1002 /$ pbc. 27905 .

5. Stieglitz E, Mazor T, Olshen AB, et al. Genome-wide DNA methylation is predictive of outcome in juvenile myelomonocytic leukemia. Nat commun 2017; 8(1): 2127. doi: 10.1038/s41467-017-02178-9.

6. Murakami N, Okuno Y, Yoshida K, et al. Integrated molecular profiling of juvenile myelomonocytic leukemia. Blood. 2018; 131(14): 1576-1586. doi: 10.1182/blood-2017-07-798157.

\section{Hosted file}


TABLE1_20201119.pdf available at https://authorea.com/users/377360/articles/494062azacitidine-as-a-bridge-to-allogeneic-stem-cell-transplantation-in-a-patient-withjuvenile-myelomonocytic-leukemia-a-case-report 